ISSN 1112-9867

\title{
THE KNOWLEDGE AND THE USE OF PSYCHOLOGICAL SKILLS OF ANGER MANAGEMENT SKILLS AT THE BEDSIDE BY THE PHYSICIANS AND NURSES OF JAHROM UNIVERSITY OF MEDICAL SCIENCES IN 2013
}

\author{
R. Eslami Akbar ${ }^{1}$, N. Kalani ${ }^{2}$, F. Maarefi ${ }^{3}$, Z. Karami ${ }^{4}$, H. Kargar Jahromi ${ }^{5}$, M. H. \\ Modabber* $^{2}$ \\ ${ }^{1}$ Assistant Professor, Dept of Nursing. Nursing School of Jahrom University of Medical \\ Sciences, Jahrom, Iran \\ ${ }^{2}$ Medical ethic research center, jahrom university of medical sciences,jahrom, Iran \\ ${ }^{3}$ Educator, Dept of Nursing. Nursing School of Jahrom University of Medical Sciences, \\ Jahrom, Iran \\ ${ }^{4}$ Educator, Dept of Nursing. Nursing School of Jahrom University of Medical Sciences, \\ Jahrom, Iran \\ ${ }^{5}$ Research center for non.communicable disease, Jahrom university of medical sciences, \\ Jahrom, Iran
}

Published online: 15 May 2016

\begin{abstract}
Although all individuals could be exposed to the outburst of anger, a group of them are more at risk than others because of the nature of their work and responsibilities, that the physicians and nurses are placed in this group. In the field of psychology, different skills such as social protection systems, problem-solving skills, self-relaxation system, use of humor skills and communication and negotiation skills have been proposed to control anger. Given the importance of anger management in the prevention of job violence in the health environment and its impact on psychological health of psychiatrists and nurses and also the lack of information and research on the topic, this study aimed to study the knowledge and the use of psychological skills of anger management at the bedside by the physicians and nurses of Jahrom University of Medical Sciences.
\end{abstract}

Author Correspondence, e-mail: Mhm3733@yahoo.com

doi: http://dx.doi.org/10.4314/jfas.v8i3s.280 
Methodology: This study is a cross-sectional and descriptive research, its studied sample included 259 general practitioners, specialists and nurses working in two general hospitals affiliated to Jahrom University of Medical Sciences. They were included in the study by the census method. The data was collected by the self-report method and two researcher-made questionnaires: a questionnaire of the knowledge of the psychological skills of anger management and a questionnaire of the use of anger management skills at the bedside and their validity (face and content) and reliability were examined before performing the research. Data analysis was performed with descriptive statistics (mean, frequency, percentage) using SPSS software.

Results: The mean of the knowledge of the physicians and nurses of Jahrom University of Medical Sciences from the psychological skills of anger management was 30.2 (standard deviation is equal to 1.53) that based on the classification of the scores of related questionnaire, it was at a good level. Also, the results showed that the mean of the use of psychological skills of anger management at the bedside by the physicians and nurses working in Jahrom University of Medical Sciences was 39.54 (standard deviation is equal to 1.28) that based on the classification of the scores of related questionnaire, it was at a good level.

Conclusion: According to the results, the knowledge and the use of psychological skills of anger management skills at the bedside by the physicians and nurses of Jahrom University of Medical Sciences were at the desired level, however, it is proposed to use other evaluation and assessment methods which have no limitations of self-report method in future studies.

Key words: anger management skill, nurses, physicians

\section{INTRODUCTION}

Anger is a satisfying thrill and also, it can be devastating, it activates our inner system prepares us to face the potential dangers around. It has harmful effects on both self and others and inability to manage anger causes incompatibility and results in harmful consequences of aggressive behavior in addition to personal discomfort, disruption of public health and interpersonal relationships (1). Therefore, anger management is a very important issue in the field of psychology and diverse skills such as the use of social protection systems, problem solving skills, Self-relaxation skills, the skills to maintain internal control, the use of humor skills, training speaking skills and effective dialogue (communication and negotiation), listening skills and expressing your feelings explicitly have been propped to control anger (2). For example, research studies have shown that people who use the social protection system 
skills i.e. the ability to communicate well and have poor social support, are more optimistic towards life. Using the method of problem solving would increase the self-confidence and it has a relationship with personal compatibility. The purpose of using self-relaxation skills such as deep breathing, distraction and ... is to maintain and control the organism against the daily pressures and stresses. The skill of maintaining internal control means dominating the life issues, accepting the responsibilities of the behaviors and trying to solve different problems. Listening to what people are saying is an effective skill to show effective solution to people and to solve many misunderstandings. In fact, the studies showed that promoting the coping and communicating skills and social psychosocial capabilities are effective in managing the control and improve the lives of individuals (2). But, it must be said that although all individuals could be exposed to the outburst of anger, a group of them are more at risk than others (3). For example, in this field, Shahsavari et al. (2005) wrote the nature of the work of nurses is such that if they are careless for a moment, there will be the possibility of serious injury to patients. A shortage of nurses and increased workload, working in shifts in a row, inadequate rest due to the shifts in circulation, suffering from patients and their families' mourning are only a part of the nursing activities that are potentially stressful. In a study by the National Institutes of Occupational Health on the relative incidence of health problems in stressful jobs, it was announced that among 130 studied jobs, nurses were placed in the $27^{\text {th }}$ rank in terms of going to physicians for the problems caused by the lack of psychological health (3). On the other hand, an overview of the database also shows that one of the main factors reducing the quality of working life and the satisfaction of employees is workplace violence that also is another stressful factor for the staff in the treatment center. For example, in the study performed in Arak by Yusefi et al., the results show that of 205 medical students and physicians, $39.45 \%$ and $53.06 \%$ of them experienced physical violence and verbal violence, respectively. In another study performed in Netherlands by Jankowik et al. (2007), it was shown that about 80 percent of physicians working in inpatient centers and $91 \%$ of physicians working in outpatient centers experienced verbal violence and more than $50 \%$ of them has injured physically. In addition to physicians, other health care professionals such as nurses and emergency medical personnel are also at the high risk of nonfatal workplace violence (4) and the risk of violence from patients and relatives of patients is 16 times higher than the incidence of this problem by health care workers against themselves (5). For example, in a study by Vinestanli (2004) to evaluate the level of physical violence, threatening behavior and verbal aggression from patients or their relatives against the different professional staff and in the different departments of a public hospital, the results 
showed that aggression against a variety of health care professionals and in different parts of the hospital is common so that in the past year, 27 percent of participants in the study were attacked, $23 \%$ of them experienced the threatening behavior of patients and $15.5 \%$ of them experienced the threatening behavior of patients' relatives. This study also showed that more than $68 \%$ of nurses had experienced verbal violence by patients and their relatives and $27.5 \%$ of them had experienced it regularly and monthly. However, despite the multiple stressful factors existing in the medical and nursing professions, there are a few studies on the knowledge and the use of psychological skills by the health personnel, particularly physicians and nurses for anger management and in this case, only a few studies can be noted, for example, a study by Shirazi et al.(2010) entitled "anger management (case study: nurses working in Imam Reza (AS), Birjand", the results of this study showed that $23.1 \%$ of nurses had no control on their anger and in this regard, his results are consistent with the results of the study performed in Isfahan by Ahmadi and Daheghi (7). Islamian et al. performed a study with the aim of identifying the effect of anger management training to the nurses of emergency department on the incidence of violence against them by patients or their relatives in two groups in Isfahan Al-Zahra Hospital, the results showed that after intervention in the studied group, their ability to manage their anger had significantly increased $(p=0.001)$ but, no significant increase occurred in the control group. On the other hand, the results showed that after intervention, there is a significance difference between the studied group and control group in terms of the psychological violence $(\mathrm{p}=0.04)$ and the studied group experience this type of violence less than control group. The researcher concluded that the increase in selfcontrol, communication and problem-solving skills, when the nurses are dealing with the patients and their relatives, is the first step in reducing one of the causes of violence in the workplace (5). Thus, given the importance of the issue, i.e. knowing and using the skills of control and management of occupational stressors such as anger management skills in health workers employed in hospitals and since, firstly, the basic information such as the knowledge and the use of such skills must be existed to do any invention program to enhance the capabilities of health workers in terms of the reaction such as anger to the stress in the workplace; and also, given the lack of significant research in this field; the researchers of this study has tried to perform a study with the aim of investigating the knowledge and the use of psychological skills of anger management skills at the bedside by the physicians and nurses of Jahrom University of Medical Sciences in 2013 to clarify the situation in the field to take the first step for future planning by the authorities in order to maintain or improve the capabilities of health personnel in the management of professional stressors. 


\section{METHODOLOGY}

This study is a descriptive and cross-sectional research. After the adoption of the plan and getting a referral from the University, the researchers admitted to the hospitals where the research samples are working in and started the research after obtaining the consent of studied units for participating in the study. The data was collected by the questionnaire designed on the demographic characteristics of the samples and the knowledge and the use of anger management skills at the bedside. The population includes all nurses and physicians (general and specialist) working in the hospitals affiliated Jahrom University of Medical Sciences that the nursing staff working in the pediatric wards, ICU, NICU, operating rooms and also, anesthesiologist, pediatrician and radiologists were excluded from the population because of some different underlying factors and conditions affecting the relations between nurses and physicians and patients or their relatives in the above mentioned items compared to other. Some of these factors are that the patients are young in the pediatric wards and NICU, there is a limited communication between caregivers and the operating room personnel; slight presence of anesthetists and radiologist at the bedside compared to other professionals that given the research field included in the questionnaire, all of them can overshadow the results and reduce the reliability of the results.

Anger management inventory:

Anger management inventory includes 8 questions on the knowledge of anger management skills which was designed with 5-point Likert scale (very much (5), much (4), average (3), little (2), very little (1)) to answer. Total score of the questionnaire is 40 and according to the classification based on multiplying the score considered for each degree of the scale by the number of questions, the score (1-16) means little knowledge of anger management skills, the score (17-24) means average, the score (24-32) means good and the score (33-40) means much and the inventory of the use of anger management skills at the bedside includes 14 items on the use of anger management skills in dealing with the patients and their relatives at the bedside which was designed based on 5-point Likert scale (always (5), often (4), sometimes (3), rarely (2) and never (1)) and the studied samples should answer the questions according to their own situations. Total score of the questionnaire is 56 and according to the classification based on multiplying the score considered for each degree of the scale by the number of questions, the score (0-14) means little use of anger management skills, the score (15-28) means average, the score (28-42) means good and the score (43-56) means much. It should be noted that the reliability (face-content) of the research tools was investigated by 
using the comments of 9 faculty members and the internal reliability of the questionnaire was investigated by asking 25 individuals of the samples including general practitioners, specialists and nurses to fill out the questionnaires in a preliminary study. The alpha was estimated 0.91 and 0.81 for the questionnaire of the knowledge and the questionnaire of the use of anger management skills, respectively. The descriptive and analytical statistics were used for data analysis and it was done by the use of SPSS software. The data were analyzed by the use of central and dispersion indices. To compare the mean score of knowledge and use of anger management skills and demographic variables (age, gender, education, etc.), t-test and ANOVA were used after investigating the normality of the data distribution by Kolmogorov test and if the data distribution was not normal, the alternative non-parametric test would be used.

\section{RESULTS}

In this study, 259 persons were participated that 238 of them were nurses (91.9\%), 14 of them were general practitioners $(5.4 \%)$ and 6 of them were specialists. Table 1 shows other demographic and occupational information of the nurses and physicians participating in the study.

Table1. Distribution of frequency and percentage of some demographic and occupational information of the nurses and physicians participating in the study

\begin{tabular}{|l|l|l|l|}
\hline \multicolumn{2}{|l|}{ Variable distribution } & Frequency & Percentage \\
\hline Gender & Male & 94 & 36.6 \\
\hline Married situation & Female & 162 & 63 \\
\hline & Single & 97 & 38.8 \\
\hline Education & Married & 153 & 62.2 \\
\hline & Associate & 1 & 0.5 \\
\hline & Bachelor & 166 & 83.8 \\
\hline & Master & 12 & 6.1 \\
\hline \multirow{2}{*}{ employment } & Basic medicine & 12 & 6.1 \\
\hline department of nurses & Surgery & 5 & 2.5 \\
\hline & Medical expertise & 64 & 31.4 \\
\hline & Maternity ward & 37 & 38.7 \\
\hline
\end{tabular}




\begin{tabular}{|l|l|l|l|}
\hline & Emergency & 5 & 2.5 \\
\hline & CCU & 12 & 5.9 \\
\hline & Post CCU & 2 & 0.1 \\
\hline
\end{tabular}

The results also showed that the average age of physicians and nurses was 27.77 (sd. was equal to 5.95) and the average work experience of them was 4.22 (sd. was equal to 3.90).

The results also showed that the mean of the knowledge of psychological skills of anger management was estimated 30.2 (sd. was equal to 1.53) that according to the classification of the scores of the questionnaire, the knowledge of psychological skills of anger management was at the level of good knowledge. Table 2 shows the detailed data on the frequency distribution of knowledge of each of psychological anger management skills based on the questionnaire scale.

Table2. The frequency distribution of knowledge of each of psychological anger management skills based on the questionnaire scale

\begin{tabular}{|c|c|c|c|c|c|}
\hline $\begin{array}{l}\text { Frequency } \\
\text { (percentage) of } \\
\text { the knowledge } \\
\text { Psychological } \\
\text { anger } \\
\text { management } \\
\text { skills }\end{array}$ & Very little & little & Average & Much & Very much \\
\hline $\begin{array}{l}\text { social protection } \\
\text { system }\end{array}$ & $\begin{array}{l}7 \\
(2.7 \%)\end{array}$ & $\begin{array}{l}23 \\
(8.9 \%)\end{array}$ & $\begin{array}{l}90 \\
(35 \%)\end{array}$ & $\begin{array}{l}98 \\
(38.1 \%)\end{array}$ & $\begin{array}{l}39 \\
(15.2 \%)\end{array}$ \\
\hline $\begin{array}{l}\text { problem-solving } \\
\text { process }\end{array}$ & $\begin{array}{r}9 \\
(3.5 \%)\end{array}$ & $\begin{array}{r}38 \\
(14.8 \%)\end{array}$ & $\begin{array}{r}127 \\
(49.4 \%)\end{array}$ & $\begin{array}{r}74 \\
(28.8 \%)\end{array}$ & $\begin{array}{r}9 \\
(3.5 \%)\end{array}$ \\
\hline Self- relaxation & $\begin{array}{r}4 \\
(1.6 \%)\end{array}$ & $\begin{array}{r}26 \\
(10.2 \%)\end{array}$ & $\begin{array}{r}100 \\
(39.4 \%)\end{array}$ & $\begin{array}{r}88 \\
(36.6 \%)\end{array}$ & $\begin{array}{r}35 \\
(13.8 \%)\end{array}$ \\
\hline $\begin{array}{l}\text { Maintaining } \\
\text { internal control }\end{array}$ & $\begin{array}{r}7 \\
(2.8 \%)\end{array}$ & $\begin{array}{r}31 \\
(12.2 \%)\end{array}$ & $\begin{array}{r}93 \\
(36.6 \%)\end{array}$ & $\begin{array}{r}93 \\
(36.6 \%)\end{array}$ & $\begin{array}{r}30 \\
(11.8 \%)\end{array}$ \\
\hline Humor skills & $\begin{array}{r}5 \\
(2 \%)\end{array}$ & $\begin{array}{r}37 \\
(15 \%)\end{array}$ & $\begin{array}{r}73 \\
(29.7 \%)\end{array}$ & $\begin{array}{r}73 \\
(29.7 \%)\end{array}$ & $\begin{array}{r}23 \\
(9.3 \%)\end{array}$ \\
\hline $\begin{array}{l}\text { communication } \\
\text { and negotiation }\end{array}$ & $\begin{array}{r}6 \\
(2.3 \%)\end{array}$ & $\begin{array}{r}31 \\
(12.1 \%)\end{array}$ & $\begin{array}{r}15 \\
(5.9 \%)\end{array}$ & $\begin{array}{c}91 \\
(35.5 \%)\end{array}$ & $\begin{array}{c}91 \\
(35.5 \%)\end{array}$ \\
\hline
\end{tabular}




\begin{tabular}{|l|r|r|r|r|r|}
\hline Listening & 6 & 31 & 91 & 91 & 15 \\
& $(2.3 \%)$ & $(12.1 \%)$ & $(35.5 \%)$ & $(35.5 \%)$ & $(5.9 \%)$ \\
\hline Internal & 6 & 39 & 88 & 88 & 11 \\
dialogue & $(2.3 \%)$ & $(44 \%)$ & $(34.2 \%)$ & $(34.2 \%)$ & $(4.2 \%)$ \\
\hline
\end{tabular}

The results also showed that the mean of the use of psychological skills of anger management was estimated 39.54 (sd. was equal to 1.28) that according to the classification of the scores of the questionnaire, the use of psychological anger management skills was at the level of good knowledge. Table 3 shows the detailed data on the frequency distribution of the use of psychological anger management skills at the bedside in dealing with the patients and their relatives by the physicians and nurses based on the questionnaire scale.

Table3. The frequency distribution of the use of psychological anger management skills at the bedside in dealing with the patients and their relatives by the physicians and nurses based on the questionnaire scale.

\begin{tabular}{|c|c|c|c|c|c|}
\hline $\begin{array}{l}\text { Frequency(percentage) } \\
\text { of psychological anger } \\
\text { management skills } \\
\text { psychological anger } \\
\text { management skills }\end{array}$ & Always & Often & Sometimes & Rarely & Never \\
\hline $\begin{array}{l}\text { Expressing the thoughts } \\
\text { calmly when feeling } \\
\text { discomfort }\end{array}$ & $55(21.3 \%)$ & $116(45 \%)$ & $68(26.4 \%)$ & $10(3.9 \%)$ & $7(21.7 \%)$ \\
\hline $\begin{array}{l}\text { Listening to the angry } \\
\text { or upset audience }\end{array}$ & $40(15.5 \%)$ & $112(43.2 \%)$ & $95(36.8 \%)$ & $6(2.3 \%)$ & $2(0.8 \%)$ \\
\hline $\begin{array}{l}\text { Speaking to an audience } \\
\text { and performing } \\
\text { common agreement }\end{array}$ & $57(22.2 \%)$ & $106(41.2 \%)$ & $76(29.6 \%)$ & $16(6.2 \%)$ & $2(0.8 \%)$ \\
\hline $\begin{array}{l}\text { Using problem-solving } \\
\text { process }\end{array}$ & $35(13.6 \%)$ & $98(38 \%)$ & $101(39.1 \%)$ & $17(6.6 \%)$ & $4(1.6 \%)$ \\
\hline $\begin{array}{l}\text { Admission and doing } \\
\text { the right request of the }\end{array}$ & $60(23.3 \%)$ & $104(40.5 \%)$ & $80(31.1 \%)$ & $11(4.3 \%)$ & $(0.8 \%)$ \\
\hline
\end{tabular}




\begin{tabular}{|c|c|c|c|c|c|}
\hline audience & & & & & \\
\hline $\begin{array}{l}\text { Changing the } \\
\text { audience's view without } \\
\text { stress }\end{array}$ & $36(14 \%)$ & $108(41.9 \%)$ & $91(35.3 \%)$ & $20(7.8 \%)$ & $2(0.8 \%)$ \\
\hline $\begin{array}{l}\text { Avoid lifting sound } \\
\text { when anger from the } \\
\text { audience }\end{array}$ & $40(15.6 \%)$ & $110(43 \%)$ & $85(33.2 \%)$ & $17(6.6 \%)$ & $3(1.2 \%)$ \\
\hline $\begin{array}{l}\text { Communicating with } \\
\text { colleagues and other } \\
\text { health care team to } \\
\text { reduce stress }\end{array}$ & $40(15.6 \%)$ & $108(41.9 \%)$ & $97(37.6 \%)$ & $8(3.1 \%)$ & $3(1.2 \%)$ \\
\hline $\begin{array}{l}\text { Going to a quiet place } \\
\text { to control anger }\end{array}$ & $25(9.8 \%)$ & $126(49.6 \%)$ & $79(31.1 \%)$ & $20(7.9 \%)$ & $3(1.2 \%)$ \\
\hline $\begin{array}{l}\text { Using time to prevent } \\
\text { anger }\end{array}$ & $32(12.5 \%)$ & $96(37.5 \%)$ & $112(43.8 \%)$ & $14(5.5 \%)$ & $2(0.8 \%)$ \\
\hline Using the humor skills & $38(14.8 \%)$ & $87(34 \%)$ & $97(37.9 \%)$ & $26(10.2 \%)$ & $7(2.7 \%)$ \\
\hline $\begin{array}{l}\text { Using self-relaxation } \\
\text { techniques }\end{array}$ & $32(82.5 \%)$ & $98(38.3 \%)$ & $102(39.8 \%)$ & $21(8.2 \%)$ & $3(1.2 \%)$ \\
\hline $\begin{array}{l}\text { Dialoguing with } \\
\text { colleagues }\end{array}$ & $37(14.5 \%)$ & $120(47.1 \%)$ & $84(32.4 \%)$ & $11(4.3 \%)$ & $2(0.8 \%)$ \\
\hline $\begin{array}{l}\text { Referring the angry } \\
\text { audience to the support } \\
\text { sources }\end{array}$ & $24(9.5 \%)$ & $103(40.7 \%)$ & $103(40.7 \%)$ & $18(7.1 \%)$ & $5(2 \%)$ \\
\hline
\end{tabular}

Data analysis showed that in terms of the age, the maximum frequency distribution of the knowledge of psychological anger management skills was related to individuals with the mean age of 27.45 (sd. was 5.9) and it was 137 persons. Also, they were at the level of good knowledge of psychological anger management skills. 98 of female participant $(40.8 \%)$ and 21 of male participants $(21.2 \%)$ were at the level of good knowledge of psychological anger management skills. Also, 90 of single persons (38.6\%) and 56 of married persons (24\%) were at the level of good knowledge of psychological anger management skills.

Data analysis showed that in terms of the work experience, the maximum frequency distribution of the knowledge of psychological anger management skills was related to 
individuals with the work experience of 3.75 years (sd. was 3.48) and it was 141 persons. In terms of education, the maximum frequency distribution of the knowledge of psychological anger management skills was related to individuals with bachelor degree of nursing and it was 88 persons $(47.3 \%)$. Also, they were at the level of good knowledge of psychological anger management skills. Other participants had the associate degree, basic medical degree and medical expertise. Also, in nurses working in different sectors, the highest frequency of the knowledge of psychological anger management skills was related to the level of good knowledge that its frequency was as following: nurses of surgery department (44 persons, $61 \%$ ), nurses of internal medicine department (32 persons, 55.2\%), nurses of emergency department (23 persons, 63.9\%), nurses of cardiac intensive care department (10 persons, $83.3 \%$ ), nurses of maternity ward ( 3 persons, $60 \%$ ), nurses of after cardiac care department ( 2 persons, $100 \%$ ).

Data analysis showed that in terms of the age, the highest frequency distribution of the use of psychological anger management skills was related to individuals with the mean age of 28.01 (sd. was 5.78) and it was 154 persons. Also, they were at the level of good use of psychological anger management skills. 180 of participants $(73.5 \%)$ were at the level of good use of psychological anger management skills. 110 of female participant (72\%) and 69 of male participants $(75 \%)$ were at the level of good use of psychological anger management skills. 180 of participants $(75 \%)$ were at the level of good use of psychological anger management skills. 71 of single persons $(76.3 \%)$ and 109 of married persons $(74.1 \%)$ were at the level of good use of psychological anger management skills.

Data analysis showed that in terms of the work experience, the highest frequency distribution of the use of psychological anger management skills was related to individuals with the work experience of 4.03 years (sd. was 3.81) and it was 170 persons. In terms of education, the highest frequency distribution of the use of psychological anger management skills was related to individuals with bachelor degree of nursing and it was 108 persons (57.8\%). Also, they were at the level of good use of psychological anger management skills. Other participants had the master degree ( 7 persons, 3.7\%), basic medical degree (10 persons, $5.3 \%)$, associate degree (1 person, 5\%) and medical expertise (5 persons, 2.7\%). Also, in nurses working in different sectors, the highest frequency of the use of psychological anger management skills was related to the level of good use that its frequency was as following: nurses of surgery department (51 persons, $70.8 \%$ ), nurses of internal medicine department (43 persons, 68.3\%), nurses of emergency department (29 persons, 78.4\%), nurses of cardiac 
intensive care department (11 persons, 91.7\%), nurses of maternity ward (4 persons, 80\%), nurses of after cardiac care department (2 persons, 100\%).

\section{DISCUSSION}

Rian et al. stated that environmental factors such as high volume work, hard work, workload, daily increase inpatients, non-compliance of patient with the nurse and environmental restrictions are of the situations causing violence that makes patients prone to aggression and causes that the nurse faces with many working pressure and affects them physically and mentally (8). In this regard, all people emphasize that the main problems are the shortage of staff and heavy workload and despite the knowledge, the routine tasks of writing, management and treatment of patients are the priority for them and communication with patients is marginalized. It is believed that shortage of staff and heavy workload have caused that technical tasks during work time structure the nursing practice instead of the patients' concerns and needs and this may in turn lead that the nurse pays attention to the patients' emotional needs only during the technical care (9). Today, routine-based nursing has been raised as a serious defect which can due to the shortage of staff and heavy workload and all individuals effort to replace it with patient-centered approach and with emphasis on the integrity of the patient's personality and unique needs (10). In this study, the ability to control anger in people with different ages is different. This result is consistent with the results of the studied by Sadouk et al. (2003), Abderhalden et al. (2002), Shirazi et al. (2010) (7, 12, 11). Mental emotions, inability to control anger, specific problems such as jobs, the wife and the lack of adequate facilities are of the probable factors affecting the amount of anger. Since the ability to control the anger increases with age and work experience, it is recommended to control the factors causing the anger in the relationship with younger individuals. In this study, there is no significant relationship between the gender and anger, this result is the same as the result of the study by Ahmadi, also, no significant difference has been observed in other studies (13). In some studies, it was reported that the women's ability to control the anger was more than the men's (14), the reason of this difference could be due to the low number of men than women in the present study, in some studies, it was reported that the anger in men is more than it in women. In this study, no significant relationship was observed between the education and anger management. This result is consistent with the results of the studies by Ahmadi and Daheghi. Also, no significant relationship was observed between the married status and anger management. This result is consistent with the results of the studies by Talaii et al., Motamedi et al. and Shirazi et al., but, according to Sadouk et al., anger management in 
married individuals was more than it in single individuals. It is not consistent with the result of present study (11).

\section{REFERENCES}

Naveedy A. The Efficacy of Anger Management Training on Adjustment Skills of High School Male Students in Tehran. IJPCP. 2009; 14 (4) :394-403

Effect of Anger management Skills Training onIndividual-Social Adjustment of First-Grade Femal Secondary Education Students in Mahshahr. 3. 2009; 0 (35) :1-14

Shahsavari s, mosalanezhad 1, sobhanian s, faseleh $\mathrm{m}$. A study on physical signs of stress, mental oajtmaai omamaiy nursing staff employed in educational centers affiliated to the Faculty of medical sciences, Jahrom, 2003. Pars Journal of Medical Sciences,2(2): 10-16.

Koohestani H, Bdghcheghi N, Rezaii K, Ebrahimi fakhar H. Risk factors for workplace violence in emergency medical technician students. Iran Occupational Health Journal. 2012; 9 (2) :68-75

Eslamian, J, Hoseini Fard S. H, Tavakol T and et al. The effect of anger management by nursing staff on violence rate against them in the emergency unit. Iran J Nurs Midwifery Res. 2010 December; 15(1):337-342.

Winstanley S, Whittington R. Aggression towards health care staff in UK general hospital: variation among professions and departments, J Clin Nurs. 2004Jan; 13(1):3-10.

Shirzaei K, Miri M, Sharifzadeh G, Yaghoobi M, Hosseini K, Kazemi S. Assessment of anger management among nursing personnel of Emam Reza hospital (Birjand, 2010). Mod Care J. $2011 ; 8$ (2) :73-78

Ryan T, Hills B, Webb L. Nurse staffing levels and budgeted expenditure in acute mental health

wards: A benchmarking study. J Psychiatr Mental Health Nurs 2004; 11: 73-81.

Aien F, Alhani F, Mohammadi E, Kazemnejad A. [Marinating the interpersonal relationship:

Nurses and patients experiences of communication in pediatric wards]. Journal of Iranian nursing research 2008; 3(8,9): 71-82. (Persian)

10. Nikbakht Nasrabadi AR, Parsa Yakta Z, Emami A. [A qualitative phenomenological comparison on Iranian and Swedish nurses' experiences]. Haiat journal 2004; 10(22): 23-31. (Persian)

11- Sadock BJ, Kaplan HI, Sadock VA. Kaplan \& Sadock's synopsis of psychiatry: behavioral sciences/clinical

psychiatry. 9th ed. Philadelphia: Lippincott Williams \& Wilkins; 2003. 
14- Kar Ahmadi M, Daheghi N. Aggression and its relation with demographical index among pediatric nurses in

University Medical Sciences Hospital of Esfehan. Journal of Researches of Behavioural Sciences. 2008; 5 (1): 33-37.

\section{[Persian]}

12- Abderhalden C, Needham I, Friedli TK, Poelmans J, Dassen T. Perception of aggression among psychiatric nurses in Switzerland. Acta Psychiatr Scand Suppl. 2002; 412: 110-17.

13- Bedagh Abadi $M$. The study of aggression incidence and its related factors among pregnant women referring to Shahid Mobaini hospital in Sabzevar. Journal of Hormozgan University of Medical Scinces. 2008; 11 (1): 71-76. [Persian]

14- Azizi M. How to control our anger and aggression? Jam-e-Jam Newspaper. 2008; (8):14. [Persian]

\section{How to cite this article:}

Eslami Akbar R, Kalani N, Maarefi F, Karami Z, Kargar Jahromi H, Modabber M H. The knowledge and the use of psychological skills of anger management skills at the bedside by the physicians and nurses of jahrom university of medical sciences in 2013. J. Fundam. Appl. Sci., 2016, 8(3S), 999-1011. 